\title{
Changes of 3-monochloropropane-1,2-diol levels in crackers and biscuits during storage
}

\author{
Anna Sadowska-Rociek ${ }^{\mathbf{1}}\left[\right.$ Ewa $^{-}$Cieślik $^{\mathbf{1}}$
}

Received: 8 May 2016/ Accepted: 14 July 2016/Published online: 23 July 2016

(c) The Author(s) 2016. This article is published with open access at Springerlink.com

\begin{abstract}
We investigated the changes of free 3-monochloropropane-1,2-diol content in two groups of shortcrust pastry samples (salty crackers and sweet biscuits) stored under different conditions. The experiment involved an impact assessment of 2 packaging types (paper and polyethylene), different storage time (from 1 to 5 months) and sunlight exposure. Our results show a significant decrease in compound levels after a longer storage time, especially for samples stored in packaging paper. However, the decay rate also depended on 3-monochloropropane-1,2-diol levels in samples. Additionally, in biscuits this degradation was associated with sunlight exposure. Comparing the rate of decay in crackers and biscuits upon sunlight exposure, we found that stability of 3-monochloropropane-1,2-diol was associated with the presence of $\mathrm{NaCl}$ in crackers.
\end{abstract}

\section{Keywords 3-MCPD $\cdot$ Shortcrust pastry $\cdot$ Storage ·} Packaging

\section{Introduction}

Salty crackers and sweet biscuits made from shortcrust pastry are one of the most popular snacks all over the world being also the most important segment of the global confectionery market. On the other hand, nowadays most consumers pay attention

Anna Sadowska-Rociek

a.sadowska-rociek@ur.krakow.pl

$1 \quad$ Malopolska Centre of Food Monitoring, Faculty of Food Technology, University of Agriculture in Krakow, Balicka 122, 30-149 Krakow, Poland to food quality and safety, and the presence of chemical contaminants in food-besides microbiological hazards-is one of the basic evaluation criteria of food safety.

The basic ingredients of shortcrust pastry are flour, fats and/or oils, sugars, eggs, salt, flavourings or spices, and optionally leavening agents such as sodium bicarbonate (Zalewski 2009). Chemical reactions during baking like the Maillard reaction, lipid oxidation and caramelisation (Van Der Fels-Klerx et al. 2014) are essential for final sensorial attributes of the pastry, however, these reactions also lead to the formation of harmful components such as chloropropanols. 3-monochloropropane-1,2-diol (3-MCPD) is the most abundant chloropropanol found in foodstuff and a potential human carcinogen. The provisional maximum tolerable daily intake in the European Union is $2 \mu \mathrm{g} \mathrm{kg}^{-1}$ body weight (Hamlet et al. 2003).

In general, 3-MCPD in food can derive through 3 different pathways: acid hydrolysis, heat processing, and via 3-MCPD esters. Thus, it occurs in a wide range of other food items (Baer et al. 2010). In cereal products with a low water content $(<15 \%)$ and shortcrust pastry, 3-MCPD forms out of lipids and sodium chloride (natural or added) during baking at temperatures above $160{ }^{\circ} \mathrm{C}$ (Chung et al. 2008). White flour, salt and water alone are also sufficient to generate 3-MCPD, while sugar does seem to have a strong influence on the production of 3-MCPD (Baer et al. 2010). However, its presence turned out to be one of the factors in promoting 3-MCPD formation. Other components of the pastry (e.g baking agents) do not contribute to 3-MCPD formation during baking (Breitling-Utzmann et al. 2005). 3-MCPD can also generate from 3-MCPD esters present in fats, oils, or 
margarine used in shortcrust pastry production. In this case, free 3-MCPD is released under lipase-catalysed hydrolysis during storage and processing (Teng and Wang 2014). The presence of 3-MCPD may be due to its migration from certain types of epichlorohydrin-based paper and cellulose packaging (Chung et al. 2008). Hence, 3-MCPD was found in dried savoury and sweet foods containing salt and fat, such as crisp bread, salty crackers, biscuits, doughnuts (Svejkovská et al. 2006). Although the overall levels of 3-MCPD in bakery products are relatively low, the high amount of product consumption indicates a significant dietary source of 3-MCPD (Wenzl et al. 2007).

3-MCPD is not very stable in foods, and its amount is a result of the mass balance between formation and decomposition (Baer et al. 2010). The stability of 3-MCPD is very sensitive to both $\mathrm{pH}$ and temperature changes and to the decrease of moisture and the drop of $\mathrm{pH}$; as seen at high temperatures in cereal systems that inhibit the decay reaction. It has been shown that the storage of simple model dough for one week prior cooking produced twice the amount of 3-MCPD compared to the freshly prepared doughs (Baer et al. 2010). However, in another study (Hamlet et al. 2003), the concentration of 3-MCPD in spiked dough kept at $3{ }^{\circ} \mathrm{C}$ over $24 \mathrm{~h}$ remained unchanged. It is also presumed that 3-MCPD can be removed by both hydrolysis and photolysis methods. Nonetheless, these findings were conducted only in water, for which it has been shown that the $\mathrm{UV} / \mathrm{H}_{2} \mathrm{O}_{2}$ process takes 3-MCPD to nearly complete conversion within minutes, whereas hydrolysis at reasonable temperatures takes several months (Nienow et al. 2009). This kind of research has not been performed in food yet.

There is little information on whether packaging material for storage is associated to heat-induced 3-MCPD levels in ready-to-eat food products like crackers or biscuits. Apart from data reported by Pace and Hartman (2010) and Mezouari et al. (2015), existing data still remain unclear and incomplete in the literature. While we cannot exclude that 3-MCPD levels in food change products like biscuits and crackers are widely consumed throughout the world, these questions needed to be addressed.

Therefore, the aim of this study was to evaluate the degradation of free 3-MCPD in sweet biscuits and salty crackers during storage from 1 to 5 months. The investigation on the impact of packaging materials on 3-MCPD levels during storage was also performed. Finally, we checked the possibility of degradation of 3-MCPD upon sunlight exposure.

\section{Materials and methods}

\subsection{Chemicals and reagents}

Hexane, acetone and acetonitrile, HPLC grade for liquid chromatography LiChrosolv ${ }^{\circledR}$ were purchased from Merck KGaA, Darmstadt, Germany. Sodium chloride was purchased from Chempur SA, Piekary Śląskie, Poland. PSA (primary secondary amine), $\mathrm{C}_{18}$ (octadecyl) SPE Bulk Sorbent derived from Agilent Technologies, Santa Clara, California, USA. 3-monochloropropane-1,2-diol (3-MCPD), 3-monochloropropane-1,2-diol-d $\mathrm{d}_{5}$ (3-MCPD- $\mathrm{d}_{5}$ ) (surrogate standard, applied to calculate the recovery), 3-monobromochloropropane-1,2-diol (3-MBPD) (syringe standard, used to compensate the possible changes of extract volume and analyte signal during GC-MS analysis), and phenylboronic acid (PBA) (derivatisation agent) were obtained from Sigma-Aldrich, Saint Louis, Missouri, USA. A sodium chloride solution of $200 \mathrm{mg} \mathrm{mL}^{-1}(20 \%)$ was prepared in deionised water. Intermediate and working standard solutions of chloropropanols at concentration $2 \mu \mathrm{g} \mathrm{mL}^{-1}$ were prepared in $20 \% \mathrm{NaCl}$ solution. PBA solution was prepared by dissolving $5 \mathrm{~g}$ PBA in $20 \mathrm{~mL}$ mixture of acetone and water (19:1, v/v).

\subsection{Instrumentation}

The Varian 4000 GC/MS (Agilent Technologies, Santa Clara, California, USA) system consisting of a 3800 GC with a CP-8410 auto-injector (Bruker, Billerica, Massachusetts, USA) and a 4000 Ion Trap MS detector was used to perform the analyses. The injector was a CP1177 Split/Splitless Capillary Injector, with a temperature of $180{ }^{\circ} \mathrm{C}$, and an injection volume of $1.0 \mu \mathrm{L}$. Each injection was performed in triplicate. Chromatographic separations were conducted using a DB-5MS column $(30 \mathrm{~m} \times 0.25 \mathrm{~mm} \times 0.25 \mu \mathrm{m}$; Agilent Technologies, Santa Clara, California, USA). The GC oven was operated with the following temperature program: initial temperature $60^{\circ} \mathrm{C} \quad(1.0 \mathrm{~min})-6{ }^{\circ} \mathrm{C}$ $\min ^{-1}-190{ }^{\circ} \mathrm{C} \quad(1.0 \mathrm{~min})-30{ }^{\circ} \mathrm{C} \quad \mathrm{min}^{-1}-280{ }^{\circ} \mathrm{C}$ $(6.0 \mathrm{~min})$. The analyses were carried out with a solvent delay of $8.0 \mathrm{~min}$. Helium 5.0 (Linde Group, Munich, Germany) was used as the GC carrier gas at a flow rate of $1.0 \mathrm{~mL} \mathrm{~min}{ }^{-1}$. The ion trap mass spectrometer was operated in the internal ionisation mode, scan from $m / z 45$ to 500 . The emission current of the ionisation filament was set at $10 \mu \mathrm{A}$. The trap and the transfer line temperatures were set on 180 and $230{ }^{\circ} \mathrm{C}$, respectively. Analyses were conducted in the selected 
ion monitoring mode (SIM) based on using one quantitative ion of PBA derivatives (147 for 3-MCPD and 3-MBPD, 150 for 3-MCPD- $\mathrm{d}_{5}$ ), qualitative ions (196 for 3-MCPD, 201 for 3-MCPD-d 5 and 241 for 3-MBPD) and retention times $(17.07,17.14$ and 18.29 for 3-MCPDd5, 3-MCPD and 3-MBPD, respectively). Acquisition and processing data were performed using Varian Start Workstation software (Agilent Technologies, Santa Clara, California, USA) and NIST 2.0 library (National Institute of Standards and Technology, Gaithersburg, Maryland, USA). MS1 Minishaker (IKA, Königswinter, Germany), MPW 350 R Centrifuge (MPW Med. Instruments, Warsaw, Poland) were employed during the sample preparation. Accublock $^{\mathrm{TM}}$ (Labnet, Edison, NJ, USA) with nitrogen 5.0 (Linde Group, Munich, Germany) was used to evaporate the solvent and concentrate the extracts.

\subsection{Experimental setup}

The research material consisted of fresh shortcrust pastry cookies with sugar (sweet butter biscuits) and salty crackers. The cookie ingredients (declared by the producer) and components important for 3-MCPD formation (fat, salt, sugar and water) are summarized in Table 1 . The selection of the products was designed to verify the influence of sugar and salt presence on the 3-MCPD levels in the investigated products. However, due to the fact that the levels of 3-MCPD in cereal products are usually too low to observe significant changes during storage period, the tested samples were additionally enriched with a mixture of 3-MCPD to $40 \mu \mathrm{g} \mathrm{kg}^{-1}$.

Based on the fact that paper as well as various plastic polymers, including polyethylenes, are the most common packaging materials for biscuits and crackers (Robertson 2011), we used standard paper and polyethylene bags for our experiments, both intended for contact with food. Crackers and biscuits were homogenized and divided into 2 parts. First part of the samples was fortified with the mixture of 3-MCPD in a suitable amount of hexane. After thorough blending of the mixtures, hexane was left to evaporate, and then the mixtures were blended once again. The second part of the samples were blank samples. In each variant of storage (9 in total), 5 replicates were prepared.

The samples were packed in appropriate paper or polyethylene packaging bags and stored for a suitable period of time (1, 3, 5 months). Additionally, we applied sunlight exposure to some samples, while the rest were wrapped tightly in aluminum foil to store away from light (Fig. 1). All samples stored in paper bags were additionally put into polyethylene bags in order to avoid air contact. The storage experiment took place in an air-conditioned laboratory and the storage conditions were established according to polish standard PN-A-74859:1994 (PKN 2016); which is $18 \pm 2{ }^{\circ} \mathrm{C}$ and $45 \%$ relative air humidity. After various storage time periods, the 3-MCPD content was analyzed and compared to the initial 3-MCPD levels prior storage.

\subsection{Determination of 3-MCPD}

The analytical procedure for the validation process used in this study was described previously involving i.e. method linearity, limit of detection and quantification, precision, accuracy and uncertainty (Sadowska-Rociek et al. 2016). Briefly, the correlation coefficient of the calibration curve (range $0.5-50 \mathrm{ng} \mathrm{mL}^{-1}$ ) was higher than 0.99 , limit of detection (LOD) and limit of quantification (LOQ), estimated on the basis of the signal of the background noise were lower than 3.1 and $9.3 \mu \mathrm{g} \mathrm{kg}^{-1}$, respectively. Repeatability $\left(\mathrm{RSD}_{\mathrm{r}}\right)$ and reproducibility $\left(\mathrm{RSD}_{\mathrm{R}}\right)$, both expressed as a relative standard deviation, were lower than 5.6 and $7.7 \%$, respectively. The method accuracy was determined with the recovery using spiked samples, because neither certified reference materials nor proficiency test programs for free 3-MCPD analysis in shortbread were available. The results were equal to $95.6 \%$ for biscuits and $107.8 \%$ for crackers. The relative expanded

Table 1 Ingredients and content of investigated samples

\begin{tabular}{|c|c|c|c|c|c|c|}
\hline & \multicolumn{5}{|c|}{ Content (mg $100 \mathrm{~g}^{-1}$ ) } & \multirow[t]{2}{*}{ Ingredients } \\
\hline & $\begin{array}{l}\text { Carbohydrates } \\
\text { (sugars) }\end{array}$ & Fat & Salt & Water & Others & \\
\hline Crackers & $67.4(9.1)$ & 16.3 & 1.5 & 3.1 & 11.7 & $\begin{array}{l}\text { Wheat flour, palm fat, raising agent }\left(\mathrm{NH}_{4} \mathrm{HCO}_{3}, \mathrm{NaHCO}_{3}\right) \text {, malt } \\
\text { extract, sugar, salt, emulsifier-soya lecithin }\end{array}$ \\
\hline Biscuits & $73.1(23.2)$ & 16.5 & 0.5 & 3.5 & 6.4 & $\begin{array}{l}\text { Flour, sugar, butter, palm fat, corn starch, whey powder, raising } \\
\text { agent }\left(\mathrm{NH}_{4} \mathrm{HCO}_{3}, \mathrm{NaHCO}_{3}\right) \text {, emulsifier-soya lecithin, salt, flavors, } \\
\text { acidity regulator-diphosphates }\end{array}$ \\
\hline
\end{tabular}




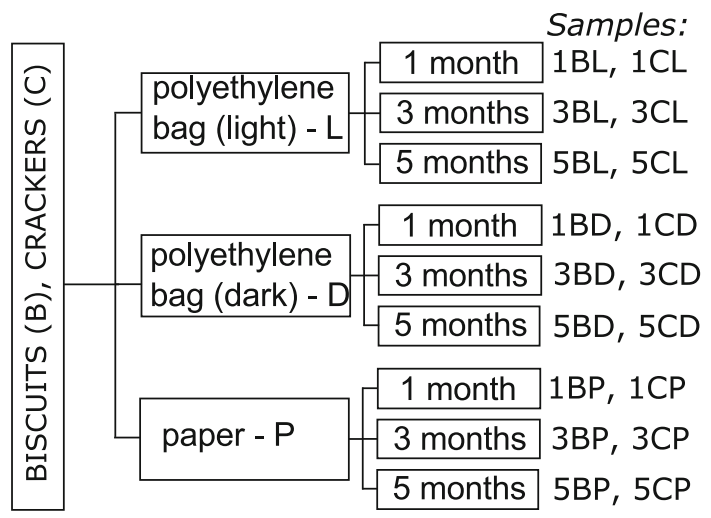

Fig. 1 Storage experiment setup

uncertainty $\left(\mathrm{rU}_{\mathrm{c}}\right)$ expressed as a percent value $(p=0.05 ; k=2)$ was estimated to be $12.3 \%$ for biscuits and $13.1 \%$ for crackers. All parameters were with in good agreement with the values established by Commission Regulation No 836/2011.

$1 \mathrm{~g}$ of the sample was weighted into a $50 \mathrm{~mL}$ centrifuge tube, spiked with 3-MCPD- $\mathrm{d}_{5}$ solution to the level of $40 \mu \mathrm{g} \mathrm{kg}^{-1}$, mixed and left to stand for $15 \mathrm{~min}$ at room temperature prior to extraction. Then, $5 \mathrm{~mL}$ of water and $10 \mathrm{~mL}$ of acetonitrile was added and the mixture was shaken vigorously for $1 \mathrm{~min}$. Next, $1 \mathrm{~g}$ of $\mathrm{NaCl}$ was added, the sample was shaken vigorously for $1 \mathrm{~min}$., and centrifuged for $15 \mathrm{~min}$ at $9000 \mathrm{rpm}$. $8 \mathrm{~mL}$ of the supernatant was transferred into a $15 \mathrm{~mL}$ glass vial and the extracts were kept in a freezer $\left(-20{ }^{\circ} \mathrm{C}\right)$ overnight to freeze out the fat. Thereafter the extract was immediately filtrated to remove precipitated co-extractives. $6 \mathrm{~mL}$ of filtrate were transferred to the $15 \mathrm{~mL}$ PP tube containing $150 \mathrm{mg}$ of PSA and $300 \mathrm{mg}$ of $\mathrm{C} 18$ sorbents. The tubes were shaken for $2 \mathrm{~min}$ and centrifuged at $10.000 \mathrm{rpm}$ for $15 \mathrm{~min}$. A volume of $2 \mathrm{~mL}$ extract was transferred into a screw cup vial and the extract was evaporated under a stream of $\mathrm{N}_{2}$ to dryness. The residues were dissolved in $100 \mu \mathrm{L}$ of $20 \% \mathrm{NaCl}$ aqueous solution and $25 \mu \mathrm{L}$ 3-MBPD solution plus $25 \mu \mathrm{L}$ PBA solutions were added. The mixture was heated up to $90{ }^{\circ} \mathrm{C}$ for $20 \mathrm{~min}$. After cooling, $0.5 \mathrm{~mL}$ hexane was added, the mixture was shaken vigorously and $200 \mu \mathrm{L}$ of upper hexane layer was transferred into an insert of an autosampler vial. The extracts were analyzed by GC-MS. Each sample was prepared in triplicates.

\subsection{Standard preparation}

A series of standard solutions were prepared to dilute standard 3-MCPD and 3-MCPD- $\mathrm{d}_{5}$ mixtures in hexane at the following concentrations: $0.5,2,5,10,30,40$, and $50 \mathrm{ng} \mathrm{mL}{ }^{-1}$. An appropriate volume of standard solution was prepared in a similar way to the samples. Each standard contained $25 \mu \mathrm{l}$ of 3-MBPD solution and was prepared in triplicates. The calibration curve was constructed by plotting integrated peak areas, divided by the area of 3-MBPD, against compound concentrations.

\subsection{Statistical analysis}

The effect of storage time, packaging material, and sunlight exposure on 3-MCPD was determined by one-way and multivariate analysis of variance (ANOVA). $p$ values of $\leq 0.05$ were considered as significant. Intergroup differences were defined by the multiple comparison method of Tukey. All analyses were performed using Statistica 12.0 software (StatSoft Inc., Tulsa, OK, USA).

\section{Results and discussion}

The storage experiment was performed for blank and spiked samples separately. The necessity of fortification resulted from a low level of 3-MCPD in the tested samples, which changes during the study would be difficult to observe and evaluate.

The content of 3-MCPD determined in all investigated samples are presented in Table 2 . We observed a decreased in 3-MCPD levels during storage in all analyzed cracker and biscuit samples. However, for blank samples of biscuits the obtained results were mostly below the limit of quantification (LOQ), established at the level of $10 \mu \mathrm{g} \mathrm{kg}^{-1}$. The rate of this decrease varied in crackers and biscuits and depended on storage conditions. In order to facilitate the assessment of 3-MCPD changes, the level expressed as $\mu \mathrm{g} / \mathrm{kg}$ was re-calculated in percentage, with respect to the initial value established as $100 \%$. The percentage values are shown in Figs. 2 and 3. Additionally, multivariate analysis of variance was performed for the evaluation of the influence of storage time and packaging material, with the exception for blank biscuit samples because the levels were below LOQ. One way ANOVA was used for the significance assessment of storage time in relation to initial samples and to estimate the significance of exposure to sunlight. All statistical results shows Table 2. 
Table 2 Content of 3-monochloropropane-1,2-diol in analysed samples

\begin{tabular}{|c|c|c|c|c|c|c|c|c|}
\hline \multicolumn{9}{|c|}{ Content of 3-MCPD $\left(\mu \mathrm{g} \mathrm{kg}^{-1}\right)$} \\
\hline \multirow{3}{*}{$\begin{array}{l}\text { Samples (storage } \\
\text { time) }\end{array}$} & \multicolumn{3}{|l|}{ Sweet biscuits } & \multirow{3}{*}{$\begin{array}{l}\text { Samples (storage } \\
\text { time) }\end{array}$} & \multicolumn{4}{|l|}{ Salty crackers } \\
\hline & \multicolumn{2}{|l|}{ Spiked } & Blank & & \multicolumn{2}{|l|}{ Spiked } & \multicolumn{2}{|l|}{ Blank } \\
\hline & \multicolumn{2}{|l|}{$\begin{array}{l}\text { Mean }(n=5) \pm \\
\text { SD }\end{array}$} & $\begin{array}{l}\text { Mean }(n=5) \pm \\
\text { SD }\end{array}$ & & \multicolumn{2}{|l|}{$\begin{array}{l}\text { mean }(n=5) \pm \\
S D\end{array}$} & \multicolumn{2}{|l|}{$\begin{array}{l}\text { mean }(n=5) \pm \\
S D\end{array}$} \\
\hline Initial & $50.5 \pm 4.9$ & & $17.0 \pm 1.5$ & Initial & $64.3 \pm 4.2$ & & $25.0 \pm 2.6$ & \\
\hline \multicolumn{8}{|c|}{ Polyethylene bag (light) } & \\
\hline $1 \mathrm{BL}$ & $47.2 \pm 0.6$ & & $15.0 \pm 1.3$ & $11 \mathrm{CL}$ & $62.9 \pm 5.2$ & & $29.4 \pm 2.4$ & \\
\hline $3 B L$ & $39.1 \pm 2.8$ & $t$ & $10.8 \pm 1.1$ & $23 \mathrm{CL}$ & $61.4 \pm 4.0$ & & $27.1 \pm 2.6$ & \\
\hline $5 B L$ & $18.3 \pm 0.4$ & $t$ & $7.0 \pm 0.5$ & $35 \mathrm{CL}$ & $57.6 \pm 1.5$ & & $25.5 \pm 2.4$ & \\
\hline \multicolumn{8}{|c|}{ Polyethylene bag (dark) } & \\
\hline $1 \mathrm{BD}$ & $40.3 \pm 0.4$ & $t$ & $9.6 \pm 0.8$ & $41 C D$ & $58.0 \pm 0.3$ & & $31.6 \pm 3.1$ & \\
\hline $3 B D$ & $37.4 \pm 1.1$ & $t$ & $9.0 \pm 0.7$ & $53 C D$ & $54.7 \pm 2.9$ & & $27.8 \pm 2.2$ & \\
\hline $5 B D$ & $35.9 \pm 2.1$ & $t I$ & $8.6 \pm 0.8$ & $65 C D$ & $52.9 \pm 1.5$ & $t$ & $23.5 \pm 1.3$ & $t$ \\
\hline \multicolumn{9}{|l|}{ Paper } \\
\hline 1BP & $25.2 \pm 1.7$ & $t p$ & $7.9 \pm 0.5$ & $71 C P$ & $56.9 \pm 0.6$ & & $21.0 \pm 1.1$ & $p$ \\
\hline 3BP & $24.5 \pm 0.9$ & $t p$ & $7.5 \pm 0.4$ & $83 C P$ & $53.3 \pm 0.3$ & & $20.5 \pm 1.2$ & $p$ \\
\hline $5 B P$ & $23.7 \pm 2.2$ & $t p$ & $8.1 \pm 0.7$ & $95 \mathrm{CP}$ & $40.6 \pm 0.7$ & $t p$ & $18.0 \pm 1.0$ & $t$ \\
\hline
\end{tabular}

Acronyms of samples: 1,3,5-storage time (in months)

$B$ biscuits, $C$ crackers, $L$ storage in polyethylene bag, exposure to light, $D$ storage in polyethylene bag, in darkness, $P$ storage in paper, $S D$ standard deviation, / statistically significant difference in 3-MCPD content affected by exposure to sunlight, $p$ statistically significant difference in 3-MCPD content affected by packaging, $t$ statistically significant difference in 3-MCPD content affected by time

Fig. 2 Changes of free 3-MCPD in crackers

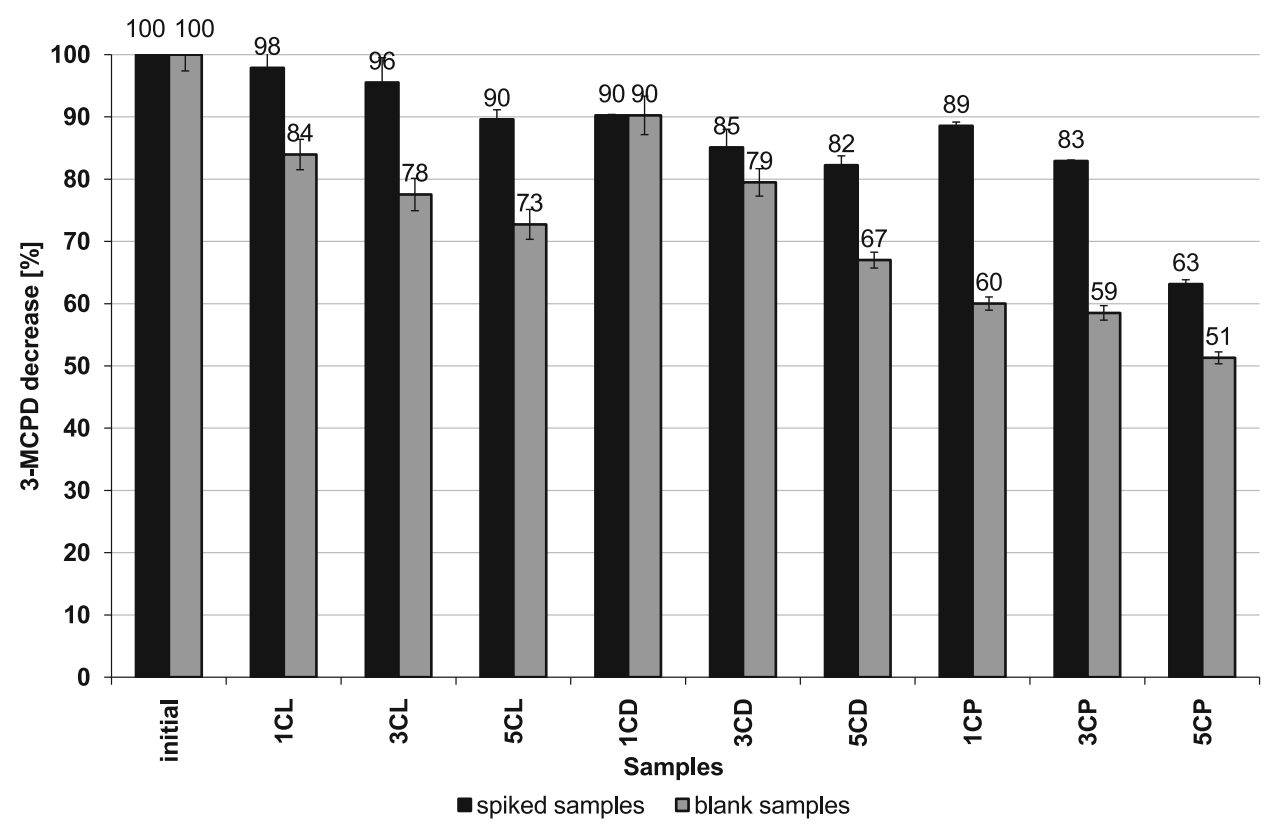

\subsection{Impact of time}

Generally, the impact of time on the 3-MCPD level varied for blank and spiked samples of crackers (Figs. 2, 3). The statistical analysis showed that the storage time had a substantial impact on the 3-MCPD level, mostly in crackers (both blank and spiked) packed in paper bags. After 1 month of storage, there was no statistically significant changes in 3-MCPD levels compared to the initial content. After 5 months of storage, a significant decrease was observed for all samples except of sample 5CL (5 months, stored in 
Fig. 3 Changes of free 3-MCPD in biscuits
100100

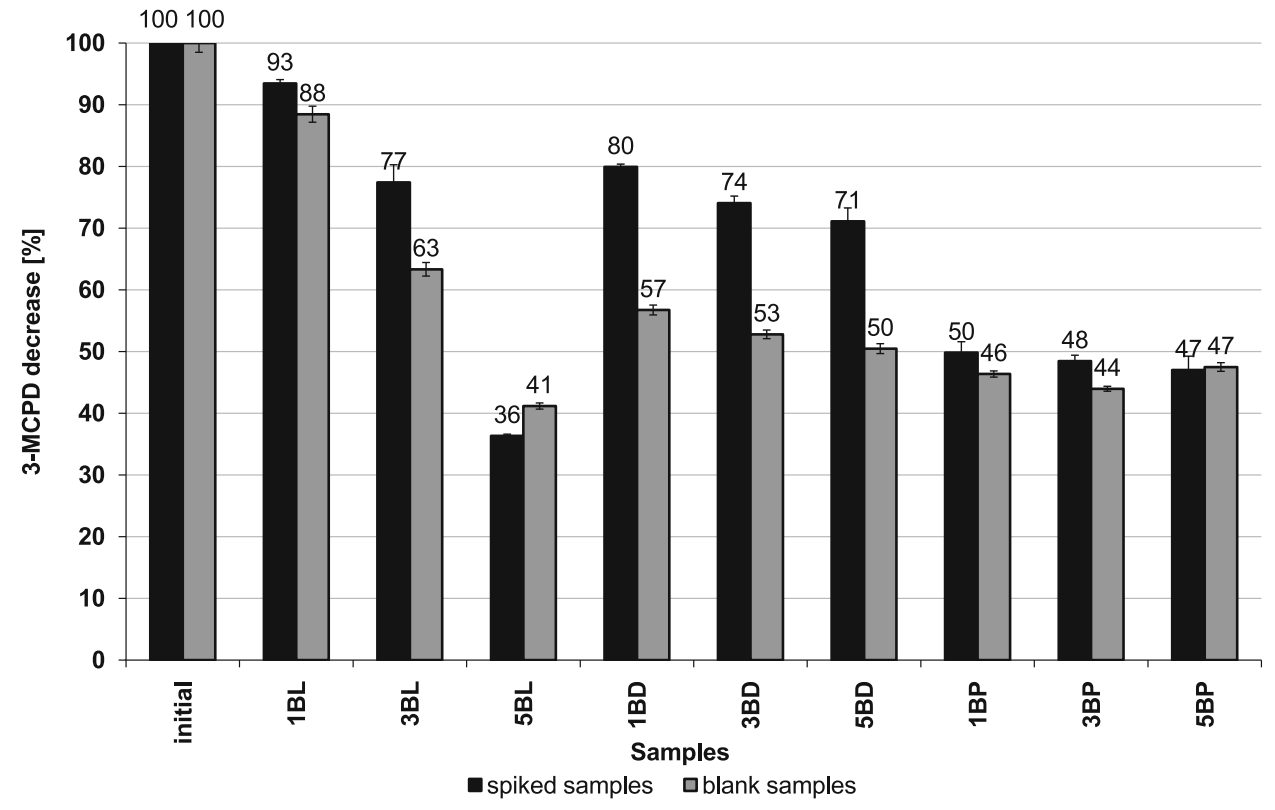

polyethylene bag, exposed to sunlight; explanation of sample acronyms were given in Fig. 1 and Table 2). Changes in 3-MCPD content between 1 and 3 months, 3 and 5 months, and 1 and 5 months of storage were generally not significant, except for the samples 3CP5CP (paper packaging), but the latter was noticed only for spiked samples.

In biscuits, there was a statistically significant decrease in 3-MCPD after 1 month of storage in all spiked samples, except for sample 1BL (stored in polyethylene bag, exposed to sunlight). Significant differences in 3-MCPD levels after 3 and 5 months of storage were noticed for all spiked samples. Changes between 1 and 3 months, 3 and 5 months, and 1 and 5 months were not big, apart for the samples 1BL-3BL, and 3BL-5BL (polyethylene bags, exposure to sunlight). For blanks, these findings were applied only in sample 3BL. For the rest of the blank samples, the results were difficult to assess due to low levels of MCPD.

\subsection{Impact of packaging}

The decrease rate in 3-MCPD level was higher in samples stored in paper bags than for those stored in polyethylene bags. The packaging had a significant impact on 3-MCPD decrease in both blank and spiked crackers (1CD-1CP, 3CD-3CP, 5CD-5CP), but the latter only in blanks. In biscuits, these differences were significant in the spiked samples 1BD-1BP, 3BD-3BP, 5BD-5BP.

\subsection{Impact of sunlight}

Sunlight did not have an effect on 3-MCPD levels in crackers, while there was a significant impact of sunlight on the decay of 3-MCPD in biscuits (5BL$5 B D)$, but only after 5 months. This could be due to the fact that it was springtime during the storage period of 3 and 5 months and with that, more sunny days that could have contributed to a faster breakdown of MCPD.

Taking all observations together, the main conclusion is the 3-MCPD instability after longer storage times. These findings confirm previous reports in the literature on 3-MCPD instability in food (BreitlingUtzmann et al. 2005). However, in our study we discovered that 3-MCPD degradation rate depended also on storage conditions and on the content of 3-MCPD in samples as well. In case of lower content of 3-MCPD in the samples (both blank samples of biscuits and crackers and spiked samples of biscuits), the 3-MCPD decay was faster, while for spiked crackers with higher 3-MCPD content, degradation has been proceeding more slowly. However, in spiked crackers and biscuits we added 3-MCPD artificially to the samples. The added 3-MCPD could be more stable in crackers, probably due to the presence of $\mathrm{NaCl}$. In biscuits, the degradation of added compound was similar to the one occurred naturally in the samples.

Apart from the 3-MCPD amount and storage time, the 3-MCPD decrease in crackers was mainly effected by the paper packaging. As for biscuits, besides 
storage time and paper packaging, the sunlight exposure had also a great impact on the decrease of 3-MCPD levels, but only in longer storage times, including sunny days. The difference between the changes of 3-MCPD levels in crackers and biscuits during sunlight exposition was the only differentiating factor in these 2 sample groups. This effect could be based on the sample ingredients. Crackers and biscuits were composed of similar water and fat, but varied in salts and sugars. This suggests once again that the presence of $\mathrm{NaCl}$ is a crucial factor contributing to 3-MCPD stability with inhibiting its degradation during exposure to sunlight.

The faster 3-MCPD decay in samples stored in paper bags might be due to the fact that paper is more susceptible to the absorption of fat, and the glycerol from fat is a precursor in the formation of 3-MCPD. According to another hypothesis, fat samples might have contained bound 3-MCPD in the form of esters, which might have decomposed over time, generating free MCPD. Absorption of fat with 3-MCPD esters by paper packaging could have inhibited the process of releasing free MCPD, in opposite to polyethylene bag.

\section{Conclusion}

To our best knowledge, the present paper is the first study concerning the free 3-MCPD stability in stored food. We conclude from our data that 3-MCPD in ready-to-eat cereal products is unstable during longer storage periods and gradually gets degraded. The largest decrease in 3-MCPD content was observed after 5-month storage in a packaging paper. In case of biscuits the decay of 3-MCPD was also significantly influenced by sunlight exposure.

These findings may contribute to extend the knowledge of the degradation mechanism of 3-MCPD in stored food products, but the practical aspect of the presented research is the possibility of decrease of the 3-MCPD level, for example by storing shortcrust pastry products packed additionally in a paper, if possible.

\section{Compliance with ethical standards}

Funding This study was funded by Ministry of Science and Higher Education of Republic of Poland within the statutory R \& D activities (DS-3707/15/KTGiK).

Conflict of interest Anna Sadowska-Rociek and Ewa Cieślik declare that they have no conflict of interest.
Ethical approval This article does not contain any studies with human participants or animals performed by any of the authors.

Informed consent Not applicable.

Open Access This article is distributed under the terms of the Creative Commons Attribution 4.0 International License (http://creativecommons.org/licenses/by/4.0/), which permits unrestricted use, distribution, and reproduction in any medium, provided you give appropriate credit to the original author(s) and the source, provide a link to the Creative Commons license, and indicate if changes were made.

\section{References}

Baer I, de la Calle B, Taylor P (2010) 3-MCPD in food other than soy sauce or hydrolysed vegetable protein (HVP). Anal Bioanal Chem 396:443-456

Breitling-Utzmann CM, Hrenn $\mathrm{H}$, Haase NU, Unbehend GM (2005) Influence of dough ingredients on 3-chloropropane-1,2-diol (3-MCPD) formation in toast. Food Addit Contam A 22(2):97-103

Chung SWC, Kwong KP, Yau JCW, Wong AMC, Xiao Y (2008) Chloropropanols levels in foodstuffs marketed in Hong Kong. J Food Comp Anal 21:569-573

Hamlet CG, Sadd PA, Gray DA (2003) Influence of composition, moisture, $\mathrm{pH}$ and temperature on the formation and decay kinetics of monochloropropanediols in wheat flour dough. Eur Food Res Technol 216:122-128

Mezouari S, Liu WY, Pace G, Hartman TG (2015) Development and validation of an improved method for the determination of chloropropanols in paperboard food packaging by GC-MS. Food Addit Contam A 32:768-778

Nienow AM, Poyer IC, Hua I, Jafvert CT (2009) Hydrolysis and $\mathrm{H}_{2} \mathrm{O}_{2}$-assisted UV photolysis of 3-chloro-1,2-propanediol. Chemosphere 75:1015-1020

Pace GV, Hartman TG (2010) Migration studies of 3-chloro-1,2propanediol (3-MCPD) in polyethylene extrusion-coated paperboard food packaging. Food Addit Contam A 27:884-891

PKN, Polish Committee for Standardization (2016) PN-A74859:1994 Preserved pastry goods-Packaging, storage and transport

Robertson GL (2011) Packaging materials for biscuits and their influence on shelf life. In: Manley D (ed) Manley's Technology of Biscuits, Crackers and Cookies, 4th edn. Woodhead Publishing, Cambridge

Sadowska-Rociek A, Cieślik E, Sieja K (2016) Simultaneous sample preparation method for determination of 3-monochloropropane-1,2-diol and polycyclic aromatic hydrocarbons in different foodstuffs. Food Anal Method. doi:10.1007/s12161-016-0486-6 (in press)

Svejkovská B, Doležal M, Velíšek J (2006) Formation and decomposition of 3-chloropropane-1,2-diol esters in models simulating processed foods. Czech J Food Sci 24:172-179

Teng Z, Wang Q (2014) Chemistry and safety of 3-MCPD. In: Yu L, Wang S, Sun B-G (eds) Food safety chemistry: toxicant occurrence, analysis and mitigation. CRC Press, Taylor \& Francis Group, Boca Raton

Van Der Fels-Klerx HJ, Capuano E, Nguyena HT, Mogol BA, Kocadağlı T, Taş NG et al (2014) Acrylamide and 5-hydroxymethylfurfural formation during baking of biscuits: 
$\mathrm{NaCl}$ and temperature-time profile effects and kinetics. Food Res Int 57:210-217

Wenzl T, Lachenmeier DW, Gökmen V (2007) Analysis of heatinduced contaminants (acrylamide, chloropropanols and furan) in carbohydrate-rich food. Anal Bioanal Chem 389:119-137

Zalewski S (2009) Basics of culinary technology. WN-T, Warsaw 